Goyanes, A; Hatton, GB; Merchant, HA; Basit, AW; (2015) Gastrointestinal release behaviour of modified-release drug products: Dynamic dissolution testing of mesalazine formulations. Int J Pharm , 484 (1-2) 103 - 108. 10.1016/.ijpharm.2015.02.051.

\title{
Article
}

\section{Gastrointestinal release behaviour of modified-release drug products: Dynamic dissolution testing of mesalazine formulations}

Alvaro Goyanes ${ }^{1}$, Grace B. Hatton ${ }^{1}$, Hamid A. Merchant ${ }^{1,2}$ and Abdul W. Basit ${ }^{1,3^{*}}$

${ }^{1}$ UCL School of Pharmacy, University College London, 29-39 Brunswick Square, London, WC1N 1AX, UK

${ }^{2}$ Current address: Department of Pharmacy, School of Applied Sciences, University of Huddersfield, Queensgate, Huddersfield HD1 3DH, UK.

${ }^{3}$ Intract Pharma, Brunswick Square, London WC1 N 1AX, UK.

${ }^{*}$ Corresponding author:

E-mail: a.basit@ucl.ac.uk

Tel: +44(0) 2077535865

Fax: +44(0) 2077535942 


\section{Abstract}

The aminosalicylate mesalazine (mesalamine) forms the mainstay of treatment in ulcerative colitis (UC); a disease for which many commercial modified-release products have been developed with the aim of providing targeted gastrointestinal release. The release profiles of five of these commercial formulations were evaluated in bicarbonate buffer using a novel dissolution model that mimics the dynamic conditions of the gastrointestinal tract. Monolithic and multi-particulate mesalazine formulations with $\mathrm{pH}$-dependent and/or independent release mechanisms were evaluated $\left(\right.$ Asacol $^{\circledR} 800$, Octasa ${ }^{\circledR}$, Mezavant ${ }^{\circledR} \mathrm{XL}$, Salofalk ${ }^{\circledR}$, Pentasa $^{\circledR}$ ), and each of the products displayed a distinctive dissolution profile. The dissolution results for Mezavant ${ }^{\circledR}$ XL $\left(\right.$ Lialda $^{\circledR}$ ) (lag time $290 \mathrm{~min}$ ) demonstrated good correlation with previously reported in vivo disintegration times assessed by gammascintigraphy in humans. Octasa ${ }^{\circledR}$ showed a similar lag time to Mezavant ${ }^{\circledR} \mathrm{XL}$. Drug release from Asacol ${ }^{\circledR} 800$ (Asacol ${ }^{\circledR}$ HD) showed a wide standard deviation, reflecting the great variability in vivo. Salofalk ${ }^{\circledR}$ displayed both delayed release and extended release characteristics. Pentasa ${ }^{\circledR}$ released more than $50 \%$ of its drug load in the stomach compartment of the model, which is attributed to the absence of a gastro-resistant coating in this product. The new dissolution method provided a realistic and discriminative in vitro assessment of mesalazine release from different formulations. These results demonstrate that this strategy can be used to predict intestinal release behaviour, and potentially aid the rational design of products developed to target different sites of the gut.

Keywords: 5- aminosalicylic acid; 5-ASA; colonic delivery; enteric coatings; biorelevant dissolution; physiological bicarbonate buffers. 


\section{Introduction}

Ulcerative colitis (UC) is one of two main entities of inflammatory bowel disease (IBD): Whereas Crohn's disease is characterised by transmural inflammation and can manifest at any membranous site along the length of the gastrointestinal (GI) tract, inflammation in UC is strictly limited to the colonic and rectal gastrointestinal mucosa. UC is also a prevalent example of a GI disorder for which oral drug delivery methods have been developed and adapted specifically with a view to minimising the risk of associated adverse drug effects, and to more specifically target the disease site(s) (McConnell et al., 2009).

Treatment strategies in UC are generally dominated by the use of aminosalicylates, with mesalazine - also known as mesalamine or 5-aminosalicylic acid (5-ASA) - as the first-line treatment indicated for UC. The exact mechanism of action of mesalazine has yet to be fully elucidated, though it is thought to act topically from the intestinal lumen to target proliferation and activity of inflammatory mediators such as prostaglandins. In this way, inflammatory "trafficking" and free radical production at disease-afflicted site(s) are considerably reduced (McConnell et al., 2009).

Following oral administration, mesalazine is normally rapidly and extensively absorbed in the upper Gl tract (Lichtenstein and Kamm, 2008). Consequently, the most commonly-used dosage forms are modified-release formulations of mesalazine. These formulations employ various strategies for drug delivery by the use of $\mathrm{pH}$-sensitive and/or insoluble polymers intended to allow for release of drug into the lower confines of the gut. Feagan et al. (2013) recently reported that all mesalazine formulations are safe and effective in the treatment of mild to moderate ulcerative colitis, however, there is evidence that patients who demonstrate inadequate response to one type of formulation benefit from switching to a different type (Yoshimura et al., 2013). This may be related to the fact that the various formulations display differences in their drug release profiles (Fadda et al., 2009; Klein et al., 2005; Schellekens et al., 2007). The choice of mesalazine therapy is also often based on trial and error, due to difficulties in tailoring individual doses to patients in addition to effective targeting of the region(s) of the gastrointestinal tract affected by disease without resulting in premature drug release (Goyanes et al., 2015a; McConnell et al., 2009).

Like all oral drug products, these mesalazine formulations are evaluated in human pharmacokinetic studies as well as clinical efficacy studies, though there is merit in developing an accurate in vitro model which best represents conditions in the human GI tract. Such a model would reduce both costs and development times through allowing early evaluation and comparison of the release profiles of various formulations simultaneously and in real time, as well as providing robust in vitro-in vivo correlations (IVIVCs).

Indeed, the design of dissolution media to accurately reflect conditions in humans and thus provide a good in vitro correlation to the in vivo situation has also been a long-standing goal for the dissolution testing of solid oral dosage forms (McAllister, 2010; Varum et al., 2013a). Compendial phosphate buffers have formed the mainstay of in vitro dissolution testing media over the years, though these systems is otherwise poorly representative of in vivo small intestinal fluid composition, leading to the rapid dissolution of enteric-coated dosage forms (Liu et al., 2009; Varum et al., 2013b). A promising alternative to the use of these standard phosphate buffers, however, are physiological bicarbonate buffers - bicarbonate being the main buffer species of human gastrointestinal luminal fluids (Fadda et al., 2009; Garbacz et al., 2013; Krieg et al., 2014)- which have been shown to better discriminate the behaviours of oral dosage forms and hence produce more accurate IVIVCs than their phosphate counterparts (Liu et al., 2011; Merchant et al., 2014).

In this work, we have evaluated a recently-developed Auto $\mathrm{pH}^{\text {System }}{ }^{\mathrm{TM}}$ that provides a closely-correlated representation of various human $\mathrm{Gl}$ parameters including $\mathrm{pH}$, ionic 
strength and buffer capacity employing a physiological bicarbonate buffer under dynamic intestinal conditions (Goyanes et al., 2015b; Merchant et al., 2012; Varum et al., 2014). We studied the feasibility of using the system to evaluate the dissolution behaviours of five commercial modified-release formulations of mesalazine. Each of the formulations herein features a slightly different release mechanism as intended for inflammatory bowel diseases.

\section{Materials and Methods}

\section{Materials}

The salts for preparing the buffer solutions were obtained from VWR International Ltd (Poole, UK) and the commercial products of mesalazine tested in this study are as follows:

Asacol ${ }^{\circledR} 800$ mg MR tablets (Asacol ${ }^{\circledR}$ HD in USA) (Warner Chilcott UK Ltd., UK) is a tablet formulation with a double-layered enteric coating comprising Eudragit $S$ (methacrylic acid methyl methacrylate copolymers (1:2)) and Eudragit L (methacrylic acid - methyl methacrylate (1:1)) which have a dissolution $\mathrm{pH}$ threshold of 7 and 6 respectively. The inner coating is Eudragit $S$ and the outer coating is a mixture of Eudragit $S$ and $L$ (Fadda et al., 2009), however, the ratio of Eudragit $S$ and $L$ in the outer coat is not disclosed.

Mezavant ${ }^{\circledR}$ XL 1200 mg tablets (Lialda ${ }^{\circledR}$ in USA) (Shire Pharmaceutical Ltd., UK) is a tablet formulation with a sustained release hydrophilic/lipophilic matrix core known as the Multi Matrix System ${ }^{\circledR}\left(\mathrm{MMX}^{\mathrm{TM}}\right)$ (Cosmo, Milan, Italy) and an outer enteric coating comprising Eudragit $S$ and $L$, however, the ratio of Eudragit $S$ and $L$ is not disclosed.

Octasa ${ }^{\circledR} 800 \mathrm{mg}$ MR tablets (Tillotts Pharma UK Ltd, UK) is a tablet formulation coated with Eudragit S.

Pentasa ${ }^{\circledR} 500$ mg tablets (Ferring Pharmaceuticals Ltd., UK) are made of the compressed ethylcellulose coated granules, where drug release from granules is mediated by diffusion through the insoluble polymer coat.

Salofalk ${ }^{\circledR} 500$ mg granules (Apriso ${ }^{\circledR} 0.375 \mathrm{~g}$ in USA) (Dr. Falk Pharma UK Ltd., UK) are gastric-resistant (Eudragit $L^{\circledR}$ coated) granules, offering prolonged drug release from a matrix core centred on the $\mathrm{pH}$-independent polymer, Eudragit $\mathrm{NE}$.

\section{Methods}

\section{Design and development of the physiological dynamic dissolution method}

Two physiological salt solutions predominately buffered by bicarbonate ions were modulated to exhibit the physiological intestinal $\mathrm{pH}$ following gastric emptying. The media are primarily a bicarbonate buffer in which bicarbonate $\left(\mathrm{HCO}_{3}{ }^{-}\right)$and carbonic acid $\left(\mathrm{H}_{2} \mathrm{CO}_{3}\right)$ co-exist in an equilibrium, along with $\mathrm{CO}_{2}(\mathrm{aq})$ resultant from the dissociation of the carbonic acid. The $\mathrm{pH}$ of the buffer system can be altered by adjusting the concentration of carbonic acid $\left(\mathrm{H}_{2} \mathrm{CO}_{3}\right)$ and bicarbonate $\left(\mathrm{HCO}_{3}{ }^{-}\right)$, the conjugate base, according to the Henderson-Hasselbalch equation. $\mathrm{pH}$ can be decreased by purging $\mathrm{CO}_{2}(\mathrm{~g})$ in the solution, which promotes the 
formation of carbonic acid. Similarly, to decrease the carbonic acid $\left(\mathrm{H}_{2} \mathrm{CO}_{3}\right)$ to bicarbonate $\left(\mathrm{HCO}_{3}{ }^{-}\right)$ratio, an inert gas (such as Helium) is purged into the solution, which removes the dissolved $\mathrm{CO}_{2}$ from the solution and therefore reduces the concentration of carbonic acid, reducing the $\mathrm{pH}$ of the media. The purging of gases is controlled by an Auto $\mathrm{pH}$ System ${ }^{\mathrm{TM}}$ (Merchant et al., 2012), automatically triggered by a pH feedback from the dissolution vessel (Figure 1). The Auto $\mathrm{pH}$ System ${ }^{\mathrm{TM}}$ consists of a $\mathrm{pH}$ probe connected to a source of carbon dioxide gas ( $\mathrm{pH}$ reducing gas), as well as to a supply of helium ( $\mathrm{pH}$ increasing gas), controlled by a control unit. The control unit monitors changes in $\mathrm{pH}$ of the bicarbonate buffer and, as appropriate, feeds $\mathrm{pH}$ increasing and/or $\mathrm{pH}$ reducing gas from the supplies into the dissolution vessel. The control unit is able to provide a dynamically adjustable $\mathrm{pH}$ during testing (dynamic conditions) and to maintain a uniform $\mathrm{pH}$ value over the otherwise unstable bicarbonate buffer $\mathrm{pH}$. Under dynamic conditions, the automated switching of the buffer $\mathrm{pH}$ between pre-defined set points allows the instrument to mimic the changing $\mathrm{pH}$ found in the gastrointestinal tract. Detailed information on the system can be found in Merchant et al., (2012).

A two-tiered bicarbonate-based buffer was used in this study. Initially, a modified Hanks buffer (mHanks) based dissolution media (Liu et al., 2011) (950 mL) was used, which followed the gastric phase, for the first $35 \mathrm{~min}(136.9 \mathrm{mM} \mathrm{NaCl}, 5.37 \mathrm{mM} \mathrm{KCl}, 0.812 \mathrm{mM}$

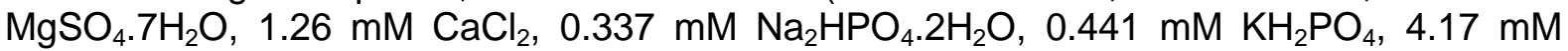
$\mathrm{NaHCO}_{3}$ ). Subsequently, $50 \mathrm{~mL}$ of pre-Krebs solution $\left(400.7 \mathrm{mM} \mathrm{NaHCO}_{3}\right.$ and $6.9 \mathrm{mM}$ $\mathrm{KH}_{2} \mathrm{PO}_{4}$ ) was added to each dissolution vessel which forms an in-situ modified Kreb's (mKreb's) buffer (Fadda et al., 2009). These media closely resemble the ionic composition and buffer capacity of the intestinal fluids (Fadda et al., 2009; Liu et al., 2011). The buffer capacity of the physiological bicarbonate buffers representing the upper small intestine, lower small intestine and colon $(3.1,3.4$ and $13 \mathrm{mM} / \mathrm{L} / \Delta \mathrm{pH}$ respectively (Fadda et al., 2009; Liu et al., 2011)), closely matches the buffer capacity of the intestinal fluids collected from the upper small intestine, lower small intestine and colon of humans (3.2, 6.4 and 13 $\mathrm{mM} / \mathrm{L} / \Delta \mathrm{pH}$ respectively (Fadda et al., 2010)).

\section{Test conditions}

The drug release from the commercial formulations was tested using a USP-II apparatus (Model PTWS, Pharmatest, Hainburg, Germany). To replicate the conditions of the GI tract the tablets or granules were initially placed for $2 \mathrm{~h}$ into $750 \mathrm{~mL}$ of $0.1 \mathrm{M} \mathrm{HCl}$; and subsequently into $950 \mathrm{~mL}$ of modified Hanks based dynamic physiological dissolution medium for $35 \mathrm{~min}$ ( $\mathrm{pH} 5.6$ to 7); then in mKrebs buffer ( $\mathrm{pH} 7$ to 7.4 and then to 6.5). The $2 \mathrm{~h}$ acid stage simulates the gastric residence time, the $3.5 \mathrm{~h}$ in bicarbonate buffer at $\mathrm{pH} 5.6$ to 7.4 represents the transit time through the small intestine, followed by a drop in buffer $\mathrm{pH}$ (6.5) which represents the colonic environment. These conditions were selected based on literature data to represent conditions for intestinal transit of pharmaceutical dosage forms and $\mathrm{pH}$ values in different segments of the GI tract in a "typical" fasted individual (Davis et al., 1986; Evans et al., 1988; Freire et al., 2011; Ibekwe et al., 2008a; McConnell et al., 2008a; Nugent et al., 2001).

The paddle speed was fixed at $50 \mathrm{rpm}$ and the tests were conducted at $37 \pm 0.5^{\circ} \mathrm{C}(\mathrm{n}=6)$. The amount of mesalazine released from commercial formulations was determined using an in-line UV spectrophotometer (Cecil 2020, Cecil Instruments Ltd., Cambridge, UK) at the wavelength of $310 \mathrm{~nm}$ for samples from the acid media and of $330 \mathrm{~nm}$ for those in bicarbonate buffer media. Data were processed using Icalis software (Icalis Data Systems Ltd, Berkshire, UK). 


\section{Results and discussion}

The physiological bicarbonate based dynamic dissolution media showed a high control of the $\mathrm{pH}\left( \pm 0.01 \mathrm{pH}\right.$ units) using the Auto $\mathrm{pH}$ System ${ }^{\mathrm{TM}}$. The $\mathrm{pH}$ was controlled within the range of $\mathrm{pH} 5.6$ to 7.4 , and it was subsequently decreased to a value of $\mathrm{pH} 6.5$ in order to simulate the dynamic $\mathrm{pH}$ conditions of the small and large intestines. Figure 2 shows a real-time $\mathrm{pH}$ profile achieved with the use of the Auto $\mathrm{pH}$ System ${ }^{\mathrm{TM}}$ at the various set points to modulate the $\mathrm{pH}$ of the media to resemble a typical fasted state $\mathrm{Gl}$ transit and $\mathrm{pH}$ profile.

The drug release performance of the mesalazine products is depicted in Figure 3 . All four enteric coated formulations were resistant to acid, showing no drug release after $2 \mathrm{~h}$ of exposure to $0.1 \mathrm{M} \mathrm{HCl}$. In the intestinal phase of the test, release from the enteric coated products was dependent on the nature of the $\mathrm{pH}$-dependent coating material. The physiological $\mathrm{pH}$ trigger of the Salofalk ${ }^{\circledR}$ product under the test conditions is 7.2. For the Asacol ${ }^{\circledR}$, Octasa ${ }^{\circledR}$ and Mezavant ${ }^{\circledR}$ products the $\mathrm{pH}$ trigger is 7.4 , but the lag times for release differ for each product. For all the enteric coated products, drug release is initiated in the small intestinal phase of the test and then continues in the colonic compartment of the test (after 330 mins). In contrast to the enteric coated formulations, in the case of Pentasa more than $50 \%$ of the drug load was released after $2 \mathrm{~h}$ of exposure to acid.

Though limited by their inability to simulate complex aspects of Gl physiology, there is much merit in developing effective and accurate in vitro models for the purpose of mimicking physiological conditions in human for mesalazine products. The true value of these models also lies in enabling extrapolation of real-time data on dissolution and distribution kinetics to inform both preclinical and clinical studies - information otherwise not readily derived from other techniques such as gamma scintigraphy, pharmacokinetic studies and gut mucosal biopsies (Lichtenstein and Kamm, 2008).

As such, the dynamic dissolution system has successfully discriminated the intestinal release behavior of the five mesalazine products. In the case of Mezavant ${ }^{\circledR} \mathrm{XL}$, the dissolution results using bicarbonate buffer under the dynamic mode correlated closely with the in vivo disintegration times of the same product from Wray et al. (2008), as assessed by gamma-scintigraphy in humans. The in vitro lag time under the dynamic conditions for Mezavant ${ }^{\circledR} \mathrm{XL}$ in this study was $290 \mathrm{~min}$, which correlates well with the initial tablet disintegration time of the same formulation in vivo (lag time $285 \mathrm{~min}$ ). The gastroresistant coating of Mezavant ${ }^{\circledR} \mathrm{XL}$ - which is a mixture of Eudragit $S$ and $L$ polymers - is designed to allow dosage form transportation to the lower gut by circumventing the harsh acidic conditions of the stomach. It is the core of Mezavant ${ }^{\circledR} \mathrm{XL}$ which is purported to extend release of drug by formation of an outer viscous gel mass on contact of the exposed core to fluid following dissolution of the coating. However, our results have shown that the release profile of mesalazine from this formulation was similar to that of the other $\mathrm{pH}$ 7-coated tablets with no apparent evidence of superior sustained release characteristics. This phenomenon was also demonstrated in a study by Fadda et al, (2009) whereupon both the lag times and drug release profiles for Mezavant ${ }^{\circledR}$ XL were shown to display different behaviours in Krebs buffer as compared to phosphate buffer, with no slow release in Krebs bicarbonate media.

By comparison, the formulations Asaco ${ }^{\circledR}$ and Octasa ${ }^{\circledR}$ showed slightly different lag times 240 and 330 min respectively (Figure 3 ). The early onset of release observed for Asacol ${ }^{\circledR}$ by comparison to Octasa ${ }^{\circledR}$ may be explained by the difference in composition of the their gastro-resistant coatings. The enteric coat of Octasa ${ }^{\circledR}$ is the Eudragit $S$ polymer, which dissolves at $\mathrm{pH}$ 7. By contrast, Asacol ${ }^{\circledR}$ comprises two enteric coatings; the inner coating is an Eudragit ${ }^{\circledR} S$ polymer, whereas the outer coating is a blend of Eudragit ${ }^{\circledR} S$ and $L$ (Fadda et al., 2009). The high standard deviation of $A$ sacol ${ }^{\circledR}$ also indicates an expected high variability in vivo (eMC-Asacol). Overall, according to the drug dissolution profiles for these products 
obtained under these standard fasted state conditions, release in vivo would take place in the last part of the small intestine and continue into the colon.

An issue with these, and similar preparations, is that a failure to disintegrate has been reported with some dosage forms in vivo. This dosage form failure might be expected in inflammatory bowel disease patients (IBD) in whom the colonic $\mathrm{pH}$ may be lower. $\mathrm{pH}$ values of $4.7 \pm 0.72$ were measured in the right colon of ulcerative colitis patients (Nugent et al., 2000 ), and a fall in colonic $\mathrm{pH}$ to $<5.5$ was found in 2 out of 6 patients studied (Fallingborg et al., 1993). In one case, a proximal colonic $\mathrm{pH}$ as low as 2.3 was detected in an ulcerative colitis patient (Fallingborg et al., 1993). However, the failure to disintegrate was also observed in healthy volunteers (McConnell et al., 2009). This led to the suggestion that $\mathrm{pH}-$ responsive dosage forms are influenced by more than just pH (lbekwe et al., 2008b), but also by residence time at the ileocaecal junction and feeding states. Gastrointestinal fluid composition is also important as the mechanism of enteric polymer dissolution in aqueous fluids is complex and influenced by a multitude of factors (Narasimhan and Peppas, 1997; Nguyen and Fogler, 2005). Hydrogen ions are generated at the polymer-solution interface during polymer dissociation (Nguyen and Fogler, 2005) and contribute to a pH drop near the surface of the dissolving carboxylic polymer (Harianawala et al., 2002). Removal of these hydrogen ions at the interface increases the polymer dissolution rate, and can be facilitated by reacting with proton acceptors (buffer species) depending on their buffer capacities, which also directly linked to the pKa of the buffering species. The rank order in the dissolution of these products can be explained by the determinant factors for enteric coating dissolution; that is, polymer pKa and chemical structure (Ozturk et al., 1988). Polymers with higher $\mathrm{pKa}$ values reflected by higher dissolution $\mathrm{pH}$ thresholds include the Eudragit ${ }^{\circledR} \mathrm{S} 100$ coated product, Octasa ${ }^{\circledR} 800$, which had slower drug release.

To circumvent some of the issues above, other approaches to $\mathrm{pH}$-responsive drug delivery to the distal gut include using polymers that have a lower $\mathrm{pH}$ threshold. In this respect for Salofalk ${ }^{\circledR} 500 \mathrm{mg}$ granules, the release of drug begins in the small intestine after $195 \mathrm{~min}-$ much earlier than for the other aforementioned products (Figure 3). This is supported by pharmacokinetic data where Salofalk ${ }^{\circledR}$ product displays a shorter time to maximum plasma concentration - 4- $5 \mathrm{~h}$ (eMC-Salofalk) - than the other enteric products, Asacol ${ }^{\circledR} 4-12 \mathrm{~h}$ (eMC-Asacol) or Mezavant ${ }^{\circledR}$ 9-12 h (eMC-Mezavant). The shorter lag time is attributable to the fact that the coating of Salofalk ${ }^{\circledR}$ is based on the polymer Eudragit $L$, which has a theoretical $\mathrm{pH}$ threshold of 6 . At this value, no release occurs, but instead only begins with a lag time delayed until pH 7.2 is achieved ( 175 mins $)$. Salofalk ${ }^{\circledR}$ is thus advantageous in potentially overcoming the "pass-through" effects noted with the other comparable formulations. However, enteric coated pellets have also been observed to pass through the gut intact (McConnell et al., 2008b). Although this approach of delayed and sustained drug release throughout small and large intestine is not very efficacious in targeting colon in ulcerative colitis but can be advantageous in patients with inflamed sites spread across the gut.

In contrast to the $\mathrm{pH}$ dependent release systems, the Pentasa ${ }^{\circledR}$ product is manufactured with a $\mathrm{pH}$ independent polymer (ethylcellulose), in consequence, the Pentasa ${ }^{\circledR}$ formulation evaluated in this study showed distinctly different behaviour in terms of its drug release as compared with the others formulations. Pentasa ${ }^{\circledR} 500 \mathrm{mg}$ tablets are comprised of compressed ethylcellulose-coated granules that degranulate rapidly in the acid stage. The drug release mechanism in this case is by diffusion through this insoluble polymer, allowing for more than $50 \%$ of drug release to take place during the acid stage with the subsequent $50 \%$ releasing throughout the entire small intestine and colon (Figure 3 ). Interestingly, the mucosal concentrations of mesalazine in the sigmoid colon is lower from this type of $\mathrm{pH}$ independent formulations compared to those receiving $\mathrm{pH}$ dependent formulations (D'Inca et al., 2013).

The physiologic dissolution system evaluated in this study can be theoretically modified to mimic different situations (real-life) such as transit time, fluid volumes and $\mathrm{pH}$ values; and it could be further improved by the addition of other luminal compounds including 
acetate/maleate and short chain fatty acids which are found in the last part of the gut. It may also be possible to mimic the environment of different disease states that we know have different Gl profiles to otherwise "normal" healthy individuals. Indeed, this can be crucial for the drug release from dosage forms designed to dissolve at a specific $\mathrm{pH}$ value which may only be maintained in the gut for a short amount of time in a given individual, and thus be potentially insufficient to allow for complete drug release. Such variations may also be apparent in disease states such as IBD, manifesting as diarrhoea and affecting the performance of modified release formulations. Whereas, altering various parameter values of the in vitro physiologic model - including $\mathrm{pH}$ and residence times - may also render it possible to evaluate robustness of these different products under different conditions.

\section{Conclusions}

The dynamic dissolution system provides a realistic in vitro simulation of the gastrointestinal tract. This system provided discriminative in vitro assessment for various commercial modified-release mesalazine formulations all run under an identical set of standard conditions reflecting typical in vivo transit and $\mathrm{pH}$ conditions. We have shown that the release profiles of five commercial formulations of mesalazine - Asacol ${ }^{\circledR} 800 \mathrm{mg}$ tablets, Mezavant ${ }^{\circledR}$ XL $1200 \mathrm{mg}$ tablets, Octasa ${ }^{\circledR} 800$ mg tablets, Pentasa ${ }^{\circledR} 500 \mathrm{mg}$ tablets and Salofalk ${ }^{\circledR} 500 \mathrm{mg}$ granules - differ considerably. These differences can be attributed to the different mechanisms used to control/modified the release of mesalazine, but owing to the highly variable physiological conditions of the Gl tract, suggests that the release of drug may equally be compromised by factors such as inter-individual variability. One of the main highlights of the study was identifying good correlation (both in vitro and in vivo lag times) for drug release from the Mezavant ${ }^{\circledR} X L$ product specifically, supporting the notion that the novel dissolution testing approach can be used as a predictive tool of in vivo results. Altering the settings of the in vitro physiologic model - including $\mathrm{pH}$ and residence times - may also render it possible to evaluate robustness of these different products under different conditions, for instance simulating disease states such as IBD, manifesting as diarrhoea and affecting the performance of modified release formulations.

\section{Acknowledgement}

Alvaro Goyanes would like to thank Fundación Alfonso Martín Escudero for the post-doctoral fellowship.

\section{Figure captions}

Figure 1. Schematic design of the Auto $\mathrm{pH}$ System ${ }^{\mathrm{TM}}$ used to modulate and maintain the $\mathrm{pH}$ of a bicarbonate buffer in a conventional USP-II apparatus. Figure adapted from Merchant et al., 2012.

Figure 2. A real-time $\mathrm{pH}$ profile of a bicarbonate based dissolution media simulating the dynamic $\mathrm{pH}$ conditions of the gut in a conventional USP-II apparatus employed for dissolution testing. The $\mathrm{pH}$ was modulated and maintained using the Auto $\mathrm{pH}^{\mathrm{TM}}$ System.

Figure 3. Drug release from the commercial formulations in $0.1 \mathrm{M} \mathrm{HCl}$ for $2 \mathrm{~h}$ followed by physiological bicarbonate buffer under dynamic $\mathrm{pH}$ conditions $(\mathrm{pH}$ ramp from 5.6 to 7.4 followed by a drop to $\mathrm{pH} 6.5$ ) controlled by the Auto $\mathrm{pH}_{\text {System }}{ }^{\mathrm{TM}}$. Red line shows real-time $\mathrm{pH}$ dissolution values. 


\section{References}

D'Inca, R., Paccagnella, M., Cardin, R., Pathak, S., Baldo, V., Giron, M.C., Sturniolo, G.C., 2013. 5-ASA colonic mucosal concentrations resulting from different pharmaceutical formulations in ulcerative colitis. World J. Gastroenterol. 19, 5665-5670.

Davis, S.S., Hardy, J.G., Fara, J.W., 1986. Transit of pharmaceutical dosage forms through the small intestine. Gut 27, 886-892.

eMC-Asacol, Summaries of Product Characteristics: Asacol 800mg MR Tablets. https://www.medicines.org.uk/emc/medicine/20478, last accessed 12-2014.

eMC-Mezavant, Summaries of Product Characteristics: Mezavant XL 1200mg, gastroresistant, prolonged release tablets. https://www.medicines.org.uk/emc/medicine/20347, last accessed 12-2014.

eMC-Salofalk, Summaries of Product Characteristics: Salofalk 500mg gastro-resistant prolonged-release granules. https://www.medicines.org.uk/emc/medicine/16909, last accessed 12-2014.

Evans, D.F., Pye, G., Bramley, R., Clark, A.G., Dyson, T.J., Hardcastle, J.D., 1988. Measurement of gastrointestinal pH profiles in normal ambulant human subjects. Gut 29, 1035-1041.

Fadda, H.M., Merchant, H.A., Arafat, B.T., Basit, A.W., 2009. Physiological bicarbonate buffers: stabilisation and use as dissolution media for modified release systems. Int. J. Pharm. 382, 56-60.

Fadda, H.M., Sousa, T., Carlsson, A.S., Abrahamsson, B., Williams, J.G., Kumar, D., Basit, A.W., 2010. Drug solubility in luminal fluids from different regions of the small and large intestine of humans. Mol. Pharm. 7, 1527-1532.

Fallingborg, J., Christensen, L.A., Jacobsen, B.A., Rasmussen, S.N., 1993. Very low intraluminal colonic pH in patients with active ulcerative colitis. Dig. Dis. Sci. 38, 1989-1993.

Feagan, B.G., Chande, N., MacDonald, J.K., 2013. Are there any differences in the efficacy and safety of different formulations of Oral 5-ASA used for induction and maintenance of remission in ulcerative colitis? evidence from cochrane reviews. Inflamm. Bowel Dis. 19, 2031-2040.

Freire, A.C., Basit, A.W., Choudhary, R., Piong, C.W., Merchant, H.A., 2011. Does sex matter? The influence of gender on gastrointestinal physiology and drug delivery. Int. J. Pharm. 415, 15-28.

Garbacz, G., Kolodziej, B., Koziolek, M., Weitschies, W., Klein, S., 2013. An automated system for monitoring and regulating the $\mathrm{pH}$ of bicarbonate buffers. AAPS PharmSciTech $14,517-522$.

Goyanes, A., Buanz, A.B., Hatton, G.B., Gaisford, S., Basit, A.W., 2015a. 3D printing of modified-release aminosalicylate (4-ASA and 5-ASA) tablets. Eur. J. Pharm. Biopharm. 89, 157-162.

Goyanes, A., Hatton, G.B., Basit, A.W., 2015b. A dynamic in vitro model to evaluate the intestinal release behaviour of modified-release corticosteroid products. J. Drug Deliv. Sci. Tec. 25, 36-42. 
Harianawala, A.I., Bogner, R.H., Bradley, M., 2002. Measurement of pH near dissolving enteric coatings. Int. J. Pharm. 247, 139-146.

Ibekwe, V.C., Fadda, H.M., McConnell, E.L., Khela, M.K., Evans, D.F., Basit, A.W., 2008a. Interplay between intestinal $\mathrm{pH}$, transit time and feed status on the in vivo performance of $\mathrm{pH}$ responsive ileo-colonic release systems. Pharm. Res. 25, 1828-1835.

Ibekwe, V.C., Khela, M.K., Evans, D.F., Basit, A.W., 2008b. A new concept in colonic drug targeting: a combined $\mathrm{pH}$-responsive and bacterially-triggered drug delivery technology. Aliment. Pharmacol. Ther. 28, 911-916.

Klein, S., Stein, J., Dressman, J., 2005. Site-specific delivery of anti-inflammatory drugs in the gastrointestinal tract: an in-vitro release model. J. Pharm. Pharmacol. 57, 709-719.

Krieg, B.J., Taghavi, S.M., Amidon, G.L., Amidon, G.E., 2014. In Vivo Predictive Dissolution: Transport Analysis of the CO2, Bicarbonate In Vivo Buffer System. J. Pharm. Sci. 103, 3473-3490.

Lichtenstein, G.R., Kamm, M.A., 2008. Review article: 5-aminosalicylate formulations for the treatment of ulcerative colitis--methods of comparing release rates and delivery of 5aminosalicylate to the colonic mucosa. Aliment. Pharmacol. Ther. 28, 663-673.

Liu, F., Lizio, R., Meier, C., Petereit, H.U., Blakey, P., Basit, A.W., 2009. A novel concept in enteric coating: A double-coating system providing rapid drug release in the proximal small intestine. J. Control. Release 133, 119-124.

Liu, F., Merchant, H.A., Kulkarni, R.P., Alkademi, M., Basit, A.W., 2011. Evolution of a physiological $\mathrm{pH} 6.8$ bicarbonate buffer system: Application to the dissolution testing of enteric coated products. Eur. J. Pharm. Biopharm. 78, 151-157.

McAllister, M., 2010. Dynamic dissolution: a step closer to predictive dissolution testing? Mol. Pharm. 7, 1374-1387.

McConnell, E.L., Fadda, H.M., Basit, A.W., 2008a. Gut instincts: Explorations in intestinal physiology and drug delivery. Int. J. Pharm. 364, 213-226.

McConnell, E.L., Short, M.D., Basit, A.W., 2008b. An in vivo comparison of intestinal pH and bacteria as physiological trigger mechanisms for colonic targeting in man. J. Control. Release 130, 154-160.

McConnell, E.L., Liu, F., Basit, A.W., 2009. Colonic treatments and targets: issues and opportunities. J. Drug Target. 17, 335-363.

Merchant, H.A., Frost, J., Basit, A.W., 2012. Apparatus and method for testing medicaments. PCT/GB2013/051145.

Merchant, H.A., Goyanes, A., Parashar, N., Basit, A.W., 2014. Predicting the gastrointestinal behaviour of modified-release products: Utility of a novel dynamic dissolution test apparatus involving the use of bicarbonate buffers. Int. J. Pharm. 475, 585-591.

Narasimhan, B., Peppas, N.A., 1997. The physics of polymer dissolution: Modeling approaches and experimental behaviour, in: Andrady, A. (Ed.), Polymer Analysis, Polymer Physics. Springer-Verlag, New York, pp. 157-207. 
Nguyen, D.A., Fogler, H.S., 2005. Facilitated diffusion in the dissolution of carboxylic polymers. AIChE J. 51, 415-425.

Nugent, S., Kumar, D., Rampton, D., Evans, D., 2001. Intestinal luminal pH in inflammatory bowel disease: possible determinants and implications for therapy with aminosalicylates and other drugs. Gut 48, 571-577.

Nugent, S.G., Kumar, D., Rampton, D.S., Yazaki, E., Evans, D.F., 2000. Gut pH and transit time in ulcerative colitis appear sufficient for complete dissolution of $\mathrm{pH}$-dependent mesalazine-containing capsules. Gut 46, A9.

Ozturk, S.S., Palsson, B.O., Donohoe, B., Dressman, J.B., 1988. Kinetics of release from enteric-coated tablets. Pharm. Res. 5, 550-565.

Schellekens, R.C.A., Stuurman, F.E., van der Weert, F.H.J., Kosterink, J.G.W., Frijlink, H.W., 2007. A novel dissolution method relevant to intestinal release behaviour and its application in the evaluation of modified release mesalazine products. Eur. J. Pharm. Sci. $30,15-20$.

Varum, F.J., Hatton, G.B., Basit, A.W., 2013a. Food, physiology and drug delivery. Int. J. Pharm. 457, 446-460.

Varum, F.J., Hatton, G.B., Freire, A.C., Basit, A.W., 2013b. A novel coating concept for ileocolonic drug targeting: proof of concept in humans using scintigraphy. Eur. J. Pharm. Biopharm. 84, 573-577.

Varum, F.J., Merchant, H.A., Goyanes, A., Assi, P., Zboranova, V., Basit, A.W., 2014. Accelerating the dissolution of enteric coatings in the upper small intestine: evolution of a novel pH 5.6 bicarbonate buffer system to assess drug release. Int. J. Pharm. 468, 172-177.

Wray, H., Joseph, R., Palmen, M., Pierce, D., 2008. Combined pharmacokinetic and scintigraphic analyses for the comparison of 5-ASA release profiles from MMX ${ }^{\mathrm{TM}}$ mesalamine and another delayed-release mesalamine formulation: P-0030. Inflamm. Bowel Dis. 14, S19-S20.

Yoshimura, N., Tadami, T., Kawaguchi, T., Sako, M., Saniabadi, A., Takazoe, M., 2013. Sa1112 Long-Term Efficacy of a pH-Dependent Release Mesalamine Formulation, Asacol in Patients With Ulcerative Colitis Who Showed Inadequate Response to a Time- Dependent Release Mesalamine Formulation, Pentasa: A Prospective study. Gastroenterology 144, S205. 